\title{
CIRRHOTIC PATIENTS;
}

Incidence, of UGI bleeding factors and esophageal varices

\section{Dr. Muhammad Adnan Bawany , Dr. Jahangir Liaquat, Dr. Muhmmad Akber, Dr. Falak Naz Shereen Rahat Khanzada, Dr. Adnan Ali Khahro, Dr. Saeed Arain}

ABSTRACT... Objective: To determine the frequency of upper GI bleeding and its predicting factors and esophageal varices in the patients with liver cirrhosis disease admitted at medicine ward of Isra university hospital. Design: Prospective and observational study. Setting: Isra university hospital. Period: March 2012 to August 2012 (six months). Methods: Containing 100 patients, mean age was 45.8 , and all the patients with cirrhosis disease were included in this study with liver cirrhosis disease. All patients were under went endoscopy and Frequency of upper Gl bleeding and varices presentation and classification according to grade were noted. Results: All the 100 patients were selected on the basis of presenting liver cirrhosis disease. Male were more found than the female with the mean age 45.8 . Mostly cirrhotic patients were found with HCV positive and upper GI bleeding were noted in (40\%) of the cases. With the endoscopic finding mostly patients were noted in II - III grad of esophageal varices and according to child pug classification majority of patients was noted in class " $\mathrm{C}$ " In addition, thrombocytopenia and red wale markings along with the presence of large sized varices were associated with the presence of esophageal varices. Conclusions: In the conclusion of this study we found majority of the cirrhotic patients with HCV, Esophageal varices and thrombocytopenia are the important factors of upper Gl bleeding. Knowledge and etiology of this manuscript may helpful in the prevention of oesophageal varices and upper Gl bleeding.

Key words: Chronic liver disease, upper Gl bleeding, varices.

Article Citation

Bawany MA, Liaquat J, Akber M, Naz F, Khanzada SR, Khoharo AA, Arain S. Cirrhotic patients; incidence, of UGI bleeding factors and esophageal varices. Professional Med J 2013;20(6): 876-881.

\section{INTRODUCTION}

Acute upper gastrointestinal bleeding is the important medical emergencies and remains a major cause of morbidity and mortality ${ }^{1}$, accounting for up to $8 \%$ hospital admissions ${ }^{2}$. UGB refers to Gastrointestinal blood loss whose origin is proximal to the ligament of Treitz ${ }^{3}$.

The incedance of UGB is 170 cases per 100,000per year, whereas prevalence of upper gastrointestinal hemorrhage (UGH)varies from 50-150 per year in USA and 100-107 per 100,000 per year in $U^{4}$. The important causes of upper gastrointestinal bleeding in our country according to locally published studies are esophageal varices, duodenal ulcer, gastric ulcers, gastric erosion, reflux esophagitis, superficial mucosal ulcer, Mallory Weiss tears, Weber rendu syndrome, arteriovenous malformation and neoplasm respectively \& in some patients no cause was found ${ }^{4}$. Most important cause of UGB in our setting is EV as compared to peptic ulcer in western countries ${ }^{5}$. The common risk factor of upper GI bleeding are cirrhosis of liver due to hepatitis B \& C, while helicobacter pylori infection, non steroidal anti inflammatory drugs in peptic ulcer ${ }^{6}$.

Variceal bleeding is one of the most serious and life threatening complication in patients with cirrhosis of liver occurs as a result of portal hypertension ${ }^{7}$. Various studies observed that gastroesophageal varices are present in almost half of cirrhotic patients (50-60\%) and about one third of these patients will experience an episode of variceal hemorrhage within one year of the diagnosis of esophageal varices ${ }^{8}$.

In the study of the Nortern Italian Endoscopic Club (NIEC), six endoscopic parameters were significantly related to variceal bleeding ${ }^{9}$. Two of these parameters were variceal size and location. Larger and more superior varices had a higher bleeding rate. Another endoscopic finding of value in predicting variceal bleeding is the appearance of the vessel wall. The color of varices is thought to predict impending hemorrhage. It has been observed that the endoscopic 
finding of "red signs" is related to the variceal bleeding $^{10}$. The "red signs" were found in $85 \%$ of large varices with bleeding. The red color signs are the result of microteleangioectasia of the varix. Variants of this sign are red wale marks, which look like whip marks; chery red spots $2 \mathrm{~mm}$ in diameter; hemocystic spots, which are round, crimson projections larger than $4 \mathrm{~mm}$ that look like blood blisters; and diffuse redness. "Cherry red spots" were noted to be dilated subepithelial veins. Hematocystic spots represent blood exiting from the deeper esophageal veins into the superficial submucosal veins. The "fundamental" color of the varices is blue or white. All the red color signs and a blue color of one varix are thought to be risk factors for bleeding. The study of NIEC showed that there was a strong correlation between a patient's Child class at the time of endoscopy and the rate of bleeding during the followup ${ }^{11}$. Most of our patients with variceal bleeding were Child's class B followed by patients with Child's class A. Ascites, hyperbilirubinemia, hypoalbuminemia, and high prothrombin time were also factors that significantly increased the risk of variceal bleeding in NIEC study. Stojanvo et al showed no significant differences in the value of cogulation parameters in patients who bled and those who did not ${ }^{10}$. The analysis of relation between the clinical and endoscopic parameters in the NIEC study has shown three variables to have independent prognostic significance for variceal bleeding: Child's class, size of varices, and the presence of red wale markings. These three variables were largely independent of each other, although size of varices and presence of red wale markings appeared somewhat related.

The most effective indicators of risk of early rebleeding are reported to be the parameters that reflect the degree of hepatic dysfunction. These include the presence of ascites, hypoalbuminemia, low prothrombin activity, encephalopathy and hyperbilirubinemia ${ }^{12}$.

\section{MATERIAL AND METHOD}

This study was containing on 100 study participants with the mean of age 48.5. All patients had an established diagnosis of chronic liver disease and were admitted in the Isra university hospital. Risk and benefit of endoscopy was discussed with patients and their relatives and Informed written consent was taken. Routine investigations including hemoglobin, hematocrit, platelets, prothrombin time, serology for hepatitis $B$ and $C$ virus, abdominal ultrasound and therapeutic upper gastro intestinal endoscopy had been carried out.

The clinical and biochemical factors as Child Pugh score, ascites, prothrombin time (PT), total bilirubin, and serum albumin were noted from selected cirrhotic patients. Ultrasonic and endoscopic findings were documented. Data were entered and analyzed in SPSS program version 16.0.

\section{RESULTS}

Total of the 100 patients were included in this study from them (65\%) were male and (35\%) were female, with the male/female ratio $2.4: 1$ and mean age was 45.8. Table-l.

\begin{tabular}{|l|c|c|}
\hline \multicolumn{1}{|c|}{ Characteristics } & Frequency & $\%$ \\
\hline Age (mean) & $(45.8)$ & - \\
\hline Male / Female & $65 / 35$ & $(65 \% / 35 \%)$ \\
\hline Anti HCV positive & 70 & $(70 \%)$ \\
\hline HBsAg positive & 20 & $(20 \%)$ \\
\hline $\begin{array}{l}\text { Both (HCV) and (HBV) } \\
\text { positive }\end{array}$ & 10 & $(10 \%)$ \\
\hline Upper Gl bleeding +ve & 40 & $(40 \%)$ \\
\hline Upper Gl bleeding - ve & 60 & $(60 \%)$ \\
\hline Child Pug classis A/B/C & $(12 / 34 / 54)$ & $(12 \% / 34 \% / 54 \%)$ \\
\hline Hemetemesis & 47 & $(47 \%)$ \\
\hline
\end{tabular}

Table-I. Baseline characteristic of cirrhotic patients with UGB and varices 
Prevalence of liver cirrhosis was in the patients of this study, HCV positive was in (70\%), HBV was positive in $(20 \%)$ and HCV and HBV both were found in (10\%). Table-l.

In all of the cirrhotic patients upper Gl bleeding was present in (40\%) and other (60\%) cases were found without bleeding while the hemetesis was occur in (47\%) of the cases of this study. Table-I.

According to child classification of this study, (12\%) patients were in class $\mathrm{A},(34 \%)$ in class B and $(54 \%)$ patients were seen in class $\mathrm{C}$. Table-l.

With the endoscopic findings in the present study esophageal varices were found in (89\%) of the patients and were distributed according to grads as, (19\%) patients were wit grad (I), (45\%) were with grad (II -III) and $(25 \%)$ patients were seen with esophageal grade (IV). Remaining (11\%) cases were noted without esophageal varices. Table-II.

\begin{tabular}{|c|c|c|}
\hline Grands of varices & Frequency & $\%$ \\
\hline I & 19 & $(19.0 \%)$ \\
\hline II - III & 45 & $(45.0 \%)$ \\
\hline IV & 25 & $(25.0 \%)$ \\
\hline Absent & 11 & $(11.0 \%)$ \\
\hline
\end{tabular}

Table-II. Gradient presantation of varices

On the basis of ultrasonic findings portal vein diameter was, mean \pm SD $(13.4 \pm 2)$ and spenic width was mean \pm SD $(52.5 \pm 4.9)$, the frequency and (\%) of biochemical and predicting bleeding factors, related with severity of cirrhosis and which are associated with presence of bleeding esophageal varices were shown in Table-III.

According to appearance of variceal bleeding risk factor, $(45 \%)$ red sign and (55\%) patients were noted with active bleeding points and variceal size were

\begin{tabular}{|l|c|}
\hline \multicolumn{1}{|c|}{ Factors } & Mean \pm SD \\
\hline AST (units/L) & $75.5 \pm 49.2$ \\
\hline ALT (units/L) & $78.0 \pm 56.4$ \\
\hline Total billirubin (mg/dl) & $2.5 \pm 1.3$ \\
\hline Alkaline Phosphatase (IU/L) & $109.8 \pm 70.9$ \\
\hline GGT & $83.2 \pm 14.2$ \\
\hline Albumin & $3.1 \pm 0.6$ \\
\hline PT secs & $19.8 \pm 6.5$ \\
\hline Platelet Count & $84.5 \pm 32.6$ \\
\hline Portal vein diameter $(>13 \mathrm{~mm})$ & $13.4 \pm 2.1$ \\
\hline Spleen width $(>50 \mathrm{~mm})$ & $52.5 \pm 4.9$ \\
\hline
\end{tabular}

Table-III. Biochemical factors associate with UGB and varices in cirrhosis patients
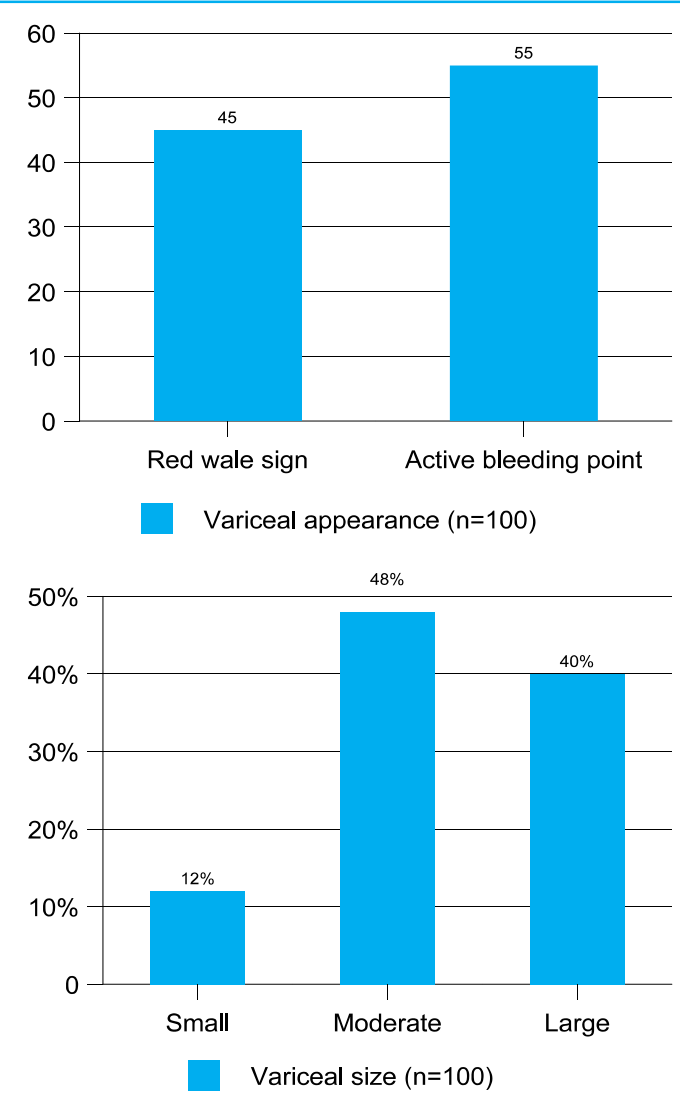

Fig-1. Variceal risk factors for esophageal bleeding 
noted as (12\%) with small size, (48\%) with moderate size and (40\%) with large size. Figure.1

\section{DISCUSSION}

Upper GIB is important medical emergency and remains a major cause of morbidity and mortality. We found in this study male were in majority than the females, with the ratio 2.4:1. Similar results were found $(66 \%)$ males and females (34\%) in the study of Fook Hong et $\mathrm{al}^{13}$ in another study reported by Schepis et al male were found (66\%) and females were noted $(34 \%)^{14}$. Mean age were found in this study was 45.8 and in other study Sheikh and associates were found (40.0) mean age in their study ${ }^{15}$.

On the bases of prevalence of cirrhosis disease in our study HCV incidence was high, as HCV was positive in (70\%), HBV was found in (20\%) and HCV and HBV both were positive in (10\%) of patients. Schepis et al, was also reported similar findings ${ }^{14}$.

During endoscopic findings of this study esophageal varices were found in (86\%) of the patients and were distributed according to grads, majority of the patients were found in grade (II - III) as, (19\%) patients were with grade $(I),(45 \%)$ were with grade $(I I-I I)$ and $(25 \%)$ patients were seen with esophageal variceal grade (IV). Remaining (14\%) cases were noted without esophageal varices. A study reported that (76.6\%) cirrhotic patients were with esophageal varices and (23.4\%) cirrhotic patients were without varices findings ${ }^{15}$. Zaman et al found (68\%) patients with esophageal varices $^{16}$.

Out of 100 cases child classification of this study, $(30 \%)$ patients were in class A, $(50 \%)$ in class B and (20\%) patients were seen in class C. According to Fook Hang et al Child classification in its study were as Childe class A was contain (26\%), Child class B (55\%) and Child class $C$ was contains (19\%) of the cases ${ }^{13}$. In another united study Zaman et al reported that patients was $(34 \%)$ in class $A,(51 \%)$ in class B and $(15 \%)$ in
Child class $\mathrm{C}^{16}$.

Several studies reported that platelet count may predict the occurrence of esophageal varices in the cirrhotic patients ${ }^{17}$. This study showed that the platelets count was mean \pm SD $(84.5 \pm 32.6)$.

Portal vien diameter was found in this study with mean \pm SD $(13.4 \pm 2.1)$. It has been reported that the normal mean portal vein diameter in Chinese populations is $9.5 \pm 1.3 \mathrm{~mm}$, while it is $11.0 \pm 0.3$ $\mathrm{mm}$ in French populations ${ }^{18}$.

Splenomegaly is documented as one of the diagnostic findings of cirrhosis disease and portal hypertension. Spleenic width was noted on ultrasonic findings in this study, mean \pm SD $(52.5 \pm 4.9)$. Many studies reported that the splenomegaly is a good predictor of esophageal varices ${ }^{19}$. Lamb et al reported that a good correlation between in vivo ultrasound assessment of splenic width and true splenic volume ${ }^{20}$.

In the present study according to appearance of variceal bleeding risk factor,(45\%) red sign and (55\%) patients were noted with active bleeding points and variceal size were noted as (12\%) with small size, $(48 \%)$ with moderate size and (40\%) with large size. Small esophageal varices were present in (10\%) patients, medium esophageal varices in (25\%) patients and large esophageal varices were noted $(65 \%)$ in patients, and the red sign were noted in (85\%) in patients with large varices ${ }^{22}$.

\section{CONCLUSIONS}

In the conclusion of this study we found majority of the cirrhotic patients with HCV, Esophageal varices mostly found as complication of hepatitis and the varices performed the very important role in upper Gl bleeding, and thrombocytopenia is rare complication and main predicting factor of esophageal bleeding. Knowledge and etiology of his manuscript may helpful in the prevention of oesophageal varices and upper Gl bleeding. 


\section{ACKNOWLEDGMENT}

Authors acknowledge Dr. Muhammad Saeed Arain for their statistical analysis using SPSS and other technical help according to guidelines.

Copyright(C) 26 June, 2013.

\section{REFERENCES}

1. Exon DJ, Sydney Chung SC. Endoscopic therapy for upper gastrointestinal bleeding. Best Pract Res Clin Gastroenterol 2004;18:77-98.

2. Abbas G, Amin K, Irshad UI Haque, Javed S. Endoscopic evaluation of upper gastrointestinal bleeding. Professional Med J 2000;7:353-7.

3. Jutabha R, Jenson DM. Acute upper gastrointestinal bleeding. In: Friedman SL, McQuaid KR, Grendell JH, editors. Current diagnosis and treatment in gastroenterology: New York: Mc-Graw-Hill; 2003. p.53-69.

4. Hussain T, Mirza S, Sabir S. Aetiology and outcome of acute upper gastrointestinal haemorrhage cases admitted to military hospital Rawalpindi. Pak Armed Forces Med J 2001;51:112-7.

5. Manning-Dimmitt LL, Dimmitt SG, Wilson GR. Diagnosis of gastrointestinal bleeding in adults. Am Fam Physician 2005;71:1339-46.

6. Khan A, Ali M, Khan IA, Khan AG. Causes of sever upper gastrointestinal bleeding on basis of endoscopic findings. J Postgrad Med Inst 2006;20(2):154-8.

7. Arguedas MR, Heudebert GR, Eloubeidi MA, Abrams G, Fallon MB. Cost-effectiveness of screening, surveillance, and primary prophylaxis strategies for esophageal varices. Am J Gastroenterol 2002; 97: 2441-2452.

8. Paunescu V, Grigorean V, Popescu C. Risk factors for immediate outcome of gastrointestinal bleeding in patients with cirrhosis. Chirurgia (Bucur) 2004; 99: $311-22$.

9. The North Italian Endoscopic Club for the Study of Esophageal Varices. Prediction to the first variceal hemorrhage in patients with cirrhosis of the liver and esophageal varices: A prospective multicenter study. N Engl J Med 1988; 319: 983-989.

10. Daniela Benedeto-Stojanov, Aleksandar Nagorni, Goran Bjelakovi , Jovica Milanovi , Dragan Stojanov; Predictive factors of bleeding from esophageal varices in patients with liver cirrhosis and portal hypertension. Medicine and Biology Vol.13, No 3, 2006, pp. 164 - 167.

11. De Franchis R, Primignani M. Why do varices bleed? Gastroent Clin N Am 1992; 21: 85-101.

12. Schalm SW, Van Buuran HR. Prevention of recurrent variceal bleeding: nonsurgical procedures. Clin Gastroenterol 1985; 14(1):209-32.

13. Ng FH, Wang SY, Loo CK, Lam KM, Lai CW, Cheng CS. Prediction of esophagogastric varices in patients with liver. cirrhosis. J Gastroenterol Hepatol 1999;14:785-90.

14. Schepis F, Calogero C, Domenico N, Magnamo A, Palio $S$, Cinquegrami, et al. Which patients with cirrhosis should. undergo endoscopic screening for esophageal varices detection? Hepatology 2001;33:333-8.

15. Shaikh NA, Khatri GK, Bhatty SA, Irfan M. Endoscopic diagnoses in patients with upper gastrointestinal bleeding. Med Channel 2010; 16:30-4.

16. Johana Prihartini*, LA Lesmana*: Chudahman Manan***, Rino A Gani.** Detection of Esophageal Varices in Liver Cirrhosis Using Non-invasive Parameters. 2005; 37(3);126-31.

17. Zaman A, Hapke R, Flora K, Rosen HR, Bemer K. Factors predicting the presence of esophageal or gastric varices in patient with advances liver disease. Am J Gastroenterol 1999;94:3292-6.

18. Thomopoulos KC, Labropoulou-Karatza C, Mimidis KP, Katsakoulis EC, Iconomou G, Nikolopoulou VN: Noninvasive predictors of the presence of large oesophageal varices in patients with cirrhosis. Dig Liver Dis 2003, 35(7):473-478.

19. He YK, Zhou H, Sun KY, Huang LX, Zhao XG, LiY, LuoXS, Christoph H, Li YS: A Study on Establishing a Normal Standard of Liver and Spleen for Ultrasonographic 
Measurement. Practical Preventive Medicine 2004, 11(3):420-422.

20. Sharma SK, Aggarwal R: Prediction of large esophageal varices in patients with cirrhosis of the liver using clinical, laboratory and imaging parameters. Journal of gastroenterology and hepatology 2007, 22(11):1909-1915.

21. Lamb PM, Lund A, Kanagasabay RR, Martin A, Webb
JA, Reznek RH: Spleen size: how well do linear ultrasound measurements correlate with threedimensional CT volume assessments? The British journal of radiology 2002, 75(895):573-577.

22. Daniela Benedeto-Stojanov ${ }^{1}$, Aleksandar Nagorni ${ }^{1}$, Goran Bjelakovi ${ }^{1}$, Jovica Milanovi ${ }^{1}$, Dragan Stojanov ${ }^{2}$. Predictive factors of bleeding from esophageal varices in patients with liver cirrhosis and portal hypertension. 2006:Vol.13, No 3,164 - 167.

\section{AUTHOR(S):}

1. DR. MUHAMMAD ADNAN BAWANY

MBBS, FCPS (Medicine)

Assistant Professor

Isra University Hospital

Hyderabad Sindh Pakistan

2. DR. JAHANGIR LIAQUAT

MBBS, MD (Medicine)

Consultant Physician

Department of Medicine

Liaquat University of Medical \&

Health Sciences, Jamshoro/Hyderabadl

3. DR. MUHMMAD AKBER

MBBS, FCPS (Medicine)

Assistant Professor

Isra University Hospital

Hyderabad Sindh Pakistan

4. Dr. Falak Naz

MBBS

Isra University Hospital

Hyderabad Sindh Pakistan
5. Shereen Rahat Khanzada

DPT (student)

Isra University Hospital

Hyderabad Sindh Pakistan

6. Dr. Adnan Ali Khahro

MBBS

Isra University Hospital

Hyderabad Sindh Pakistan

7. Dr. Saeed Arain

MBBS

Department of Medicine

Liaquat University of Medical \&

Health Sciences, Jamshoro/Hyderabad Sindh Pakistan

Correspondence Address:

Dr. Jahangir Liaquat

H No. 305-E, Unit No. 9 ,

Latifabad, Hyderabad

drjahangirliaquat@gmail.com

Article received on: 29/03/2013 Accepted for Publication: 26/09/2013 Received after proof reading: 03/12/2013

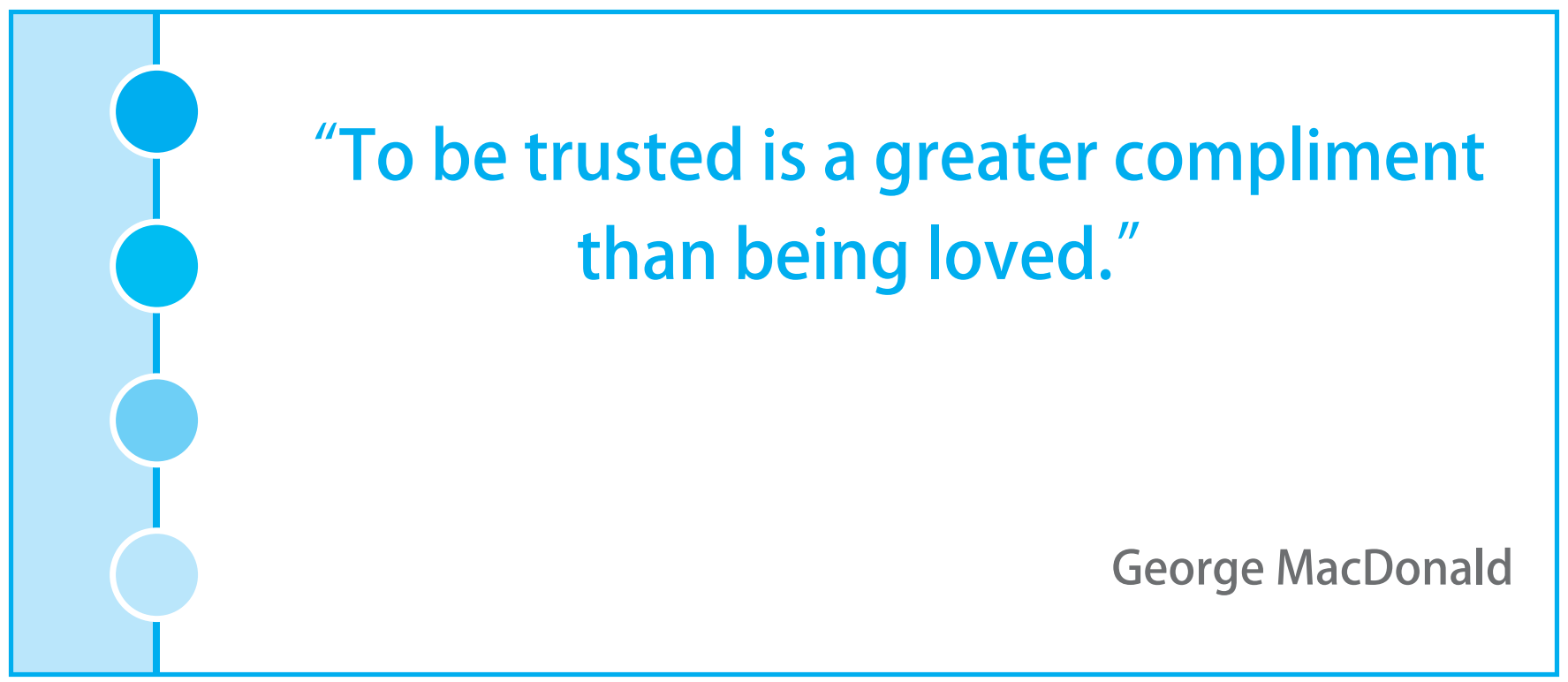

